\section{Persistence of traditional beliefs among undergraduates}

$J_{A H O D A^{1}}$, Pasachoff et $a .^{2}$, and Salter and Routledge ${ }^{3}$ have investigated the hypothesis that university education leads to the decline of supernatural beliefs, arriving at strikingly similar results that contradict the hypothesis. We carried out an extension of these studies at our institution. Our investigations were aimed at an evaluation of the persistence of traditional, Eastern beliefs among undergraduates.

One hundred and forty science undergraduates (100 male and 40 female), chosen at random, answered 14 questions on astronomy, astrology, superstitions, evil spirits, auspicious time, pilgrimage and sacred animals (Table 1 ).

The returned questionnaires were first processed by the year of study and then by sex. The options to each question-certainly believe, sometimes yes, sometimes no and certainly do not-were allotted scores of 20, 11, 9 and 0 respectively (as in ref. 1 where 0 denoted 'total unqualified disbelief' and 20, 'total unqualified belief'). For each question these scores were summed and then the sum was divided by the number of respondents, giving a 'mean belief score'. There are two questions for each topic so by averaging the

\section{TAbLe 1 The questionnaire}

This study seeks to evaluate the degree of traditional beliefs held by the students of our college. The answers shall be treated as confidential and it does not seek to evaluate individual students. Each of the questions below are provided with four options. Please indicate clearly by an ' $\mathrm{X}$ ' the option most relevant to you.

Personal data:

(i) Year of graduate study: $1 \mathrm{yr}, 2 \mathrm{yr}$ or $3 \mathrm{yr}$.

(ii) Sex: male or female.

The respondents were then asked to answer certainly believe, sometimes yes, sometimes no or certainly do not to the following questions.

\section{Astronomy:}

1. Do you believe that the stars and planets have any influence over your daily routine?

2. Do you believe that the appearance of a comet or an eclipse brings bad luck?

Astrology:

3. Do you believe in consulting your partner's horoscope before settling for marriage?

4. Do you believe in palmistry and numerology?

Superstitions:

5. Do you believe that Friday, the 13 th, is an unlucky day? 6 . Do you believe that treading on one's nails would bring mis-
fortune?

Evil spirits:

7. Do you believe that evil spirits dwell in the grave yard?

8. Do you believe in the power of witchcraft and charms?

Auspicious time:

9. Do you believe in an "auspicious time" before setting off on important ventures?

10. Do you believe that a child must be born at an "auspicious time" to be successful in life?

\section{Pilgrimage:}

11. Do you believe that the River Ganges has the ability to wash away your sins?

12. Do you believe that shaving your head fulfills your vow to
God? Sacred animals:

13. Do you believe that the peacock (bird) is a vehicle of God? 14. Do you hold snakes and cows to be sacred animals?
TABLE 2 Average belief scores by the year of graduate study

\begin{tabular}{lcccc}
\hline \multicolumn{1}{c}{ Question } & First & Second & Third & All \\
Astrology & year & year & year & years \\
Astronomy & 7.67 & 7.43 & 7.37 & 7.49 \\
Superstitions & 6.05 & 5.96 & 5.85 & 5.96 \\
Evil spirits & 8.48 & 8.16 & 8.11 & 8.25 \\
Auspicious time & 7.77 & 7.75 & 7.73 & 7.75 \\
Pilgrimage & 9.99 & 9.72 & 9.42 & 9.71 \\
Sacred animals & 7.01 & 6.95 & 6.83 & 6.93 \\
Mean & 7.07 & 6.95 & 6.62 & 6.88 \\
No. of subjects & 7.72 & 7.56 & 7.42 & 7.567 \\
\hline
\end{tabular}

two mean scores an 'average belief score' for that topic is obtained.

A score of 5 or above was taken to indicate a persistencc of beliefs. For example, with the students overall, we found an average belicf score of $\mathbf{5 . 9 6}$ for the traditions in astronomy and 9.71 for auspicious time (Table 2), indicating a greater persistence of the belief in auspicious time over the astronomical traditions.

The mean score for all students and for all the questions is 7.567, indicating the prevalence of traditional, Eastern beliefs to a marked degree among science undergraduates (Table 2). But, unlike the study at the University of Pennsylvania ${ }^{3}$, there seems to be a difference in attitude between the sexes (Table 3 ). This may be attributable to both the environment and sociology of Indian society. Table 2 also shows a very gradual decline in beliefs with increasing time spent at the university.

TABI. 3 Average belief scores by sex

\begin{tabular}{llcc}
\hline \multicolumn{1}{c}{ Question } & Male & Female & Total \\
Astrology & 6.77 & 8.21 & $\mathbf{7 . 4 6}$ \\
Astronomy & 5.81 & 6.11 & $\mathbf{5 . 9 6}$ \\
Superstitions & $\mathbf{8 . 1 6}$ & 8.34 & $\mathbf{8 . 2 5}$ \\
Evil spirits & 7.21 & 8.29 & 7.75 \\
Auspicious time & $\mathbf{9}$ & 10.06 & $\mathbf{9 . 7 1}$ \\
Pilgrimage & $\mathbf{6 . 8 4}$ & 7.02 & $\mathbf{6 . 9 3}$ \\
Sacred animals & 5.23 & 8.53 & $\mathbf{6 . 8 8}$ \\
Mean & 7.054 & 8.08 & 7.567 \\
No. of subjects & 100 & 40 & 140 \\
\hline
\end{tabular}

High scores of 9.71 and 8.25 for auspicious time and superstitions, respectively, may reflect the deep-rooted naturc of these beliefs. It was surprising that a mean scorc of 5.96 was recorded for astronomy, despite it being a finite science. The vast difference in scores for sacred animals between the sexes seems to be an examplc of the sex-differentiated attitude towards these beliefs.

In conclusion, although our study was limited to science undergraduates, the results are similar to earlier studies ${ }^{1-3}$ If traditional beliefs hinder scientific training, a way must be sought for their eradication to improve our activites in science.

We thank Dr George Abraham for support.

S. Dinesh Kumar

C. J. K. HeNry

Madras Christian College, Madras 600059

Received November 19, 1973.

1 Jahoda, G., Nature, 220, 1356 (1968).

2 Pasachoff, J. M., Cohen, R. J., and Pasachoff, N. W., Nature, 227, 971 (1970).

${ }^{3}$ Salter, C. A., and Routledge, L. M., Nature, 232, 278 (1971). 